\title{
Sensitivity, specificity, predictive value and accuracy of ultrasonography in pregnancy rate prediction in Sahelian goats after progesterone impregnated sponge synchronization
}

\author{
Justin Kouamo르. Adama Sow², Miguiri Kalandi² and Germain Jerome Sawadogo ${ }^{2}$
}

\author{
1. Department of Surgery and Medical Pathology, School of Veterinary Medicine and Sciences, The University of \\ Ngaoundere, Ngaoundere, Cameroon; 2. Laboratory of Endocrinology and Radio-immunology, Service of Biological and \\ Medical Physics and Chemistry, EISMV, Dakar, Senegal. \\ Corresponding author: Justin Kouamo, e-mail: justinkouamo@yahoo.fr, \\ AS: wosamada@yahoo.fr, MK: migson77@yahoo.fr, GJ S: sawadogo@refer.sn
}

Received: 02-05-2014, Revised: 01-08-2014, Accepted: 12-08-2014, Published online: 30-09-2014

doi: 10.14202/vetworld.2014.744-748. How to cite this article: Kouamo J, Sow A, Kalandi M, Sawadogo GJ (2014) Sensitivity, specificity, predictive value and accuracy of ultrasonography in pregnancy rate prediction in Sahelian goats after progesterone impregnated sponge synchronization, Veterinary World 7(9): 744-748.

\begin{abstract}
Aim: This study was aimed to evaluate the sensitivity, specificity, predictive value and accuracy of ultrasonography in pregnancy rate (PR) prediction in Sahelian goats after progesterone impregnated sponge synchronization within the framework of caprine artificial insemination (AI) program in Fatick (Senegal).

Materials and Methods: Of 193 candidate goats in AI program, 167 were selected (day 50) in six villages. Estrus was synchronized by progesterone impregnated sponges installed for 11 days. Two days before the time of sponge removal (day 4), each goat was treated with $500 \mathrm{IU}$ of equine chorionic gonadotropin and $50 \mu \mathrm{g}$ of dcloprostenol. All goats were inseminated (day 0) with alpine goat semen from France at $45 \pm 3 \mathrm{~h}$ after sponge removal (day 2). Real-time B-mode ultrasonography was performed at day 50, day 13, day 0, day 40 and day 60 post-AI.

Results: Selection rate, estrus response rate, AI rate, PR at days 40 and days 60 were $86.53 \%$; $71.85 \%$; 83.34\%; 51\% and $68 \%(\mathrm{p}<0.05)$ respectively. Value of sensitivity, specificity, positive and negative predictive value, accuracy, total conformity, conformity of correct positive, conformity of correct negative and discordance of pregnancy diagnosis by trans-abdominal ultrasonography (TU) were 98.03\%; 63.26\%; 73.52\%; 3.12\%; 81\%; 81\%; 50\%; 31\% and 19\%, respectively.
\end{abstract}

Conclusion: These results indicate that the TU can be performed in goats under traditional condition and emphasized the importance of re-examination of goats with negative or doubtful TU diagnoses performed at day 40 post-AI.

Keywords: accuracy, artificial insemination, estrus, pregnancy, Sahelian goats, ultrasonography.

\section{I ntroduction}

Now-a-days, ultrasonography has gained popularity in veterinary medicine and has become the most preferred method for diagnostic imaging of the various organs of the body, also including the reproductive organs [1]. The technique is based on the use of ultrasound waves to visualize genital organs noninvasively in their internal environment. The safety of this method has been officially recognized by the World Health Organization [2]. Ultrasonographic examination is a unique method, which is used for evaluation of pregnancy status and fetus number in small ruminants. Detection of hydrometra using ultrasonography is performed at 40 days of pregnancy [3]. In addition to anestrus, absence of fetus (es), and accumulation of anechoic fluid with black spots are the ultrasonographic findings of pseudopregnancy [4].

Earlier diagnostic examinations have been also suggested by trans-rectal techniques but with relatively poor applicability owing to care and labor connected

Copyright: The authors. This article is an open access article licensed under the terms of the Creative Commons Attributin License (http:// creative commons.org/licenses/by/2.0) which permits unrestricted use, distribution and reproduction in any medium, provided the work is properly cited. to fecal repletion and rectal brittleness [5]. Under field conditions, a trans-abdominal probe (linear or sector 3.5-5.0 MHz frequency) is generally used for detection of pregnancy at days 40-50 in sheep and goats by observing fluid accumulation and cotyledons [4]. Researchers have suggested high specificity (97\%), sensitivity (100\%) [6] and high accuracy rates for pregnancy (90-95\%) and non-pregnancy (100\%) diagnosis [7].

In the context of diversification of animal genetic resources, the Government of Senegal in partnership with the Poitou Charentes Region in France has launched a program of artificial insemination (AI) in goats in the region of Fatick with priority to fight against poverty especially in the traditional area. However, analysis of the results of AI since the beginning of the campaign in 2005 showed a low fertility rate (31\%) [8]. In this context, the current study has been carried out to establish a diagnosis of pregnancy by B-mode trans-abdominal ultrasonography (TU) throughout the caprine AI program in the traditional area (Fatick).

Specific objectives were to determine the selection rate, the estrus response rate and AI rate; to determine the pregnancy rates (PR) following AI and finally to evaluate the quality of the pregnancy 
diagnostic method using real-time B-mode ultrasonography in Indigenous Sahelian goats in Senegal.

\section{Materials and Methods}

Ethical approval

The experimental protocol followed the ethical guidelines on the proper care and use of animals and had been approved by the ministry of livestock.

\section{Study area and animal selection}

The study was conducted in the region of Fatick limited by the region of Kaolack in the East, the region of Thies and Atlantic Ocean in the Northwest, the Republic of Gambia and Diourbel in the South, the Region of Louga in the North and Northwest. The multiparous Sahelian goats with good conformation and with history of no abortion or dystocia in the previous gestation were chosen for the study. Of the candidate goats $(n=193), 167$ were selected after the ultrasound examination performed 50 days before AI. Ultrasonographic examination of the uterus was done using $3.5 \mathrm{MHz}$ sector-array transducer connected to a portable B-mode ultrasound scanner $\left(\operatorname{Agroscan}^{\circledR}\right)$. All the ultrasonographic examinations were done by the same observer who had experience in performing ultrasonographic pregnancy diagnosis (PD) in goats. Goats have been examined in a standing position as described by Purohit [1].

Does were selected from 6 farms in department of Fatick: Ndoffane $(n=20)$, Ndiop $(n=34)$, Thialle $(n=22)$, Maroneme $(n=28)$, Ngoyere $(n=26)$ and Mbafaye ( $n=37)$. During their stay, they received different type of straw (brush, cowpea, maize), groundnut hay and fresh water ad libitum.

\section{Estrus induction and Al}

One month before the beginning of estrus induction treatment, all selected goats were dewormed (ivermectin) and vaccinated against pasteurellosis. A TU diagnosis was performed 13 days before insemination to eliminate pregnant animals from the sample. Estrus was synchronized by means of intravaginal sponges (each containing $45 \mathrm{mg}$ flurogestone acetate; Cronolone ${ }^{\circledR}$ ) installed for 11 days (from day 13 to day 2). Two days before the time of sponge removal (day 4), each goat was treated (i.m.) with eCG (500 IU, Folligon ${ }^{\circledR}$, Intervet International B.V.) and estrumate (50 $\mu \mathrm{g}$ cloprostenol, a synthetic analog of prostaglandin $F_{2} \alpha$ ). All goats were inseminated, deep into vagina, with alpine goat semen from France at $45 \pm 3$ h after sponge removal. Inseminations were done by the same operator. The day of insemination was considered as day 0 . Estrus signs were detected at least 3 times/day: Early in the morning, about mid-day and 06:00 p.m.

\section{PD}

A PD was performed by TU at day 40 and day 60 after AI. The does have been properly restrained in a standing position during scanning [1].

\section{Evaluation of the method}

Quality criteria based on the ultrasonographic method used for $\mathrm{PD}$ in goats between day 40 and day 60 post-AI were the sensitivity, specificity, the predictive value of the diagnostic test, i.e., the probability that the diagnosis reflects the true pregnancy status [9]. The sensitivity (Se) was defined as the likelihood of a positive test result in goats. It was calculated by the following equation; $\mathrm{Se}=100 \times \mathrm{a} /(\mathrm{a}+\mathrm{c})$. Conversely, the specificity $(\mathrm{Sp})$ was defined as likelihood of a negative test result in goats known to be of non-pregnant and it was calculated by the following equation; $\mathrm{Sp}=100 \times \mathrm{d} /(\mathrm{b}+\mathrm{d})$. The positive predictive value $(+\mathrm{PV})$ would then be the probability of the presence of pregnancy in an animal diagnosed pregnant i.e., $100 \times a /(a+b)$. The negative predictive value (-PV) would be the probability of absence of pregnancy in an animal diagnosed non-pregnant i.e., $100 \times d /(c+d)$. The accuracy $(A c)=100 \times(a+d) / N$. Total conformity $=100 \times(\mathrm{a}+\mathrm{d}) / \mathrm{N}$. Conformity of correct positive $=100 \times(\mathrm{a}) / \mathrm{N}$. Conformity of correct negative $=100 \times(d) / N$. Discordance $=100 \times(b+c) / N[10]$.

\section{Statistical analysis}

All data from the selection (day 50) to BDs (day 60) were collected and analyzed using the WinPeriscope 2.0, CLIVE Education, Edinburgh, UK, software based on Microsoft windows. The positive results of BDs using ultrasonography at day 40 and day 60 were compared using the Chi-squared test. The level of significance was recorded at the $5 \%$ level of confidence [11].

\section{Results}

\section{Selection rate, estrus response rate and Al rate}

Following ultrasonographic examinations, $167 / 193$ (86.53\%) goats were selected (day 50), $120 / 167$ (71.85\%) were synchronized and induced in estrus (from day 13 to day 0) and 100/120 (83.34\%) were inseminated at day 0 (Table-1).

PR by ultrasonography at day 40 and day 60 post-Al

The ultrasonographic examination revealed 51 (51\%) and 68 (68\%) pregnancy status at day 40 and day 60, respectively (Table-2).

\section{Evaluation of the method}

Considering the pregnancy status of inseminated goats at day 40 and day 60 (Table-2), the contingency table was done. Following the above, the quality criteria have been obtained (Table-3).

\section{Discussion}

Selection rate, estrus response rate and $\mathrm{Al}$ rate

During selection (day 50), 26 goats were diagnosed pregnant and discarded after the TU examination. So, 26 fetal loss (might be due to hormonal deficiency) have been prevented at the time of selection.

The estrus response was comparable to the rate obtained by Mpatswenumugabo [12], but lower than reports of Djakba [8], Kor et al. [13], Omontese 
Table-1: Ultrasonographic results of selection, estrus response and Al.

\begin{tabular}{lccc}
\hline Localities & Selection rate (day 50) & Estrus response rate (day 13) & Al rate (day 0) \\
\hline Ndoffane $(n=20)$ & $100.00(n=20)$ & $75.00(n=15)$ & $86.67(n=13)$ \\
Ndiop $(n=34)$ & $100.00(n=34)$ & $76.47(n=26)$ & $84.61(n=22)$ \\
Thialle $(n=37)$ & $59.46(n=22)$ & $81.82(n=18)$ & $83.33(n=15)$ \\
Maroneme $(n=28)$ & $100.00(n=28)$ & $50.00(n=14)$ & $78.57(n=11)$ \\
Ngoyere $(n=29)$ & $89.65(n=26)$ & $92.30(n=24)$ & $95.83(n=23)$ \\
Mbafaye $(n=45)$ & $82.23(n=37)$ & $62.16(n=23)$ & $69.56(n=16)$ \\
Total $(n=193)$ & $86.53(n=167)$ & $71.85(n=120)$ & $83.34(n=100)$ \\
\hline
\end{tabular}

$\mathrm{n}=$ Total number of animal, $\mathrm{Al}=$ Artificial insemination

Table-2: Ultrasonographic results at day 40 and day 60 post-Al.

\begin{tabular}{lcc}
\hline Localities & $\begin{array}{c}\text { Positive } \\
\text { result by } \\
\text { ultrasonography } \\
\text { at day 40 } \\
\text { post-Al (\%) }\end{array}$ & $\begin{array}{c}\text { Positive } \\
\text { result by } \\
\text { ultrasonography } \\
\text { at day } \mathbf{6 0} \\
\text { post-Al (\%) }\end{array}$ \\
\hline Ndoffane $(n=13)$ & $30.76(n=4)$ & $23.07(n=3)$ \\
Ndiop $(n=22)$ & $68.18(n=15)$ & $81.81(n=18)$ \\
Thialle $(n=15)$ & $53.33(n=8)$ & $86.67(n=13)$ \\
Maroneme $(n=11)$ & $18.18(n=2)$ & $36.36(n=4)$ \\
Ngoyere $(n=23)$ & $56.52(n=13)$ & $69.56(n=16)$ \\
Mbafaye $(n=16)$ & $56.25(n=9)$ & $87.50(n=14)$ \\
Total $(n=100)$ & $51^{\text {a }}(n=51)$ & $68^{b}(n=68)$ \\
\hline
\end{tabular}

$a, b$ The different letters indicate that the difference is significant $(p<0.05) . n=$ Total number of animal, $\mathrm{Al}=$ Artificial insemination

Table-3: Se, Sp, +PV, -PV, Ac, TC, CCP, CCN and Di of PD by TU in Sahelian goats.

\begin{tabular}{lc}
\hline Correct positive (pregnant) $^{\mathrm{a}}$ & $\mathrm{n}=50$ \\
False positive (non-pregnant) $^{\mathrm{b}}$ & $\mathrm{n}=1$ \\
Correct negative (non-pregnant) $^{\mathrm{c}}$ & $\mathrm{n}=31$ \\
False negative (pregnant) $^{\mathrm{d}}$ & $\mathrm{n}=18$ \\
Se (\%) & 98.03 \\
Sp (\%) & 63.26 \\
+PV (\%) & 73.52 \\
-PV (\%) & 3.12 \\
AC (\%) & 81 \\
TC (\%) & 81 \\
CCP (\%) & 50 \\
CCN (\%) & 31 \\
Di (\%) & 19 \\
\hline
\end{tabular}

$\mathrm{Se}=$ Sensitivity, $\mathrm{Sp}=$ Specificity, $+\mathrm{PV}=$ Positive predictive value, $-P V=$ Negative predictive value, $A c=$ Accuracy, $\mathrm{TC}=$ Total conformity, $\mathrm{CCP}=$ Conformity of correct positive, $\mathrm{CCN}=$ Conformity of correct negative, $\mathrm{Di}=$ Discordance, $\mathrm{PD}=$ Pregnancy diagnosis, $\mathrm{TU}=$ Trans-abdominal ultrasonography

et al. [14] and Kouamo et al. [15]. This might be related to breed, nutrition, environment, estrus induction protocol [16]. In addition, 33 goats were diagnosed pregnant and discarded between day 13 and day 0 after the ultrasonographic examination. In practice, the early BDs can only be done 35 days after pregnancy. Before, it may be difficult to identify the conceptus, especially when large-sized, mature goats are scanned under field conditions [17]. In addition, 14 animals were missing at the time of sponges application (day 13), reclaimed by impatient farmers and often sold to meet the daily family needs [18].
The insemination rate is less than the $100 \%$ reported by Omontese et al. [19]; comparable to the 83\% reported by Omontese et al. [20]; but higher than reported by Djakba [8], Mpatswenumugabo [12] and Omontese et al. [14]. These variations might be related to the experimental environment, breed, and hormonal induction. The latter might cause aggressive behavior, fights between females and loss of spirals.

\section{BDs}

The establishment of a pregnancy ultrasound diagnosis is based on the detection of the presence of the conceptus. This technique also allows the determination of the vitality of the embryo by highlighting heartbeat or fetal movement. The PR at day 60 remains significantly higher than the rate obtained at day 40 , also to those reported by Mbaindingatoloum [21], Djakba [8]; comparable to the reported rate by Kouamo et al. [15] but significantly lower than the rates found by Rwakazina [22]. The low PR obtained at day 40 might be explained by artifacts such as the presence of sunlight, the poor contact or poor impact, which could lead to errors. For BDs in small ruminants, Purohit [1] recommended that the hair must be clipped from just above the udder and $15-20 \mathrm{~cm}$ ahead of the udder on both sides of the abdomen. The transducer was placed above the udder between the thigh and abdomen preferably the left side and moved in a "W" shape from one side of the abdomen to the other side. The increasing of the PR from day 40 to day 60 post-AI might be due to the low risk of errors at this stage coupled with better visibility of fetal bulbs. This study revealed that BDs examination by ultrasonography at day 60 should be recommended as a confirmatory diagnosis for non-pregnant goats or doubtful pregnancy at day 40 .

\section{Evaluation of the quality of ultrasonographic diagnosis}

The efficacy of ultrasound depends on several factors, among other equipment, sensor, and restraint of animals, animal size, pregnancy stage and experience of the operator [23]. This study shows that BDs by B-mode ultrasonography is more sensitive than specific. The values of sensitivity and specificity obtained were comparable to those obtained by Gonzalez et al. [9] and lower than those reported by Davey [24] with a sensitivity of $99 \%$ and a specificity of $100 \%$. Taverne et al. [25] have reported that the 
sensitivity and specificity of this technique were high after the $29^{\text {th }}$ day, reaching almost $100 \%$ between the $46^{\text {th }}$ and $106^{\text {th }}$ days of pregnancy.

The overall accuracy was lower than that reported by Medan et al. [26] and Gonzalez et al. [9] who found accuracy levels of $100 \%$ and $98.7 \%$, respectively. The +PV was higher than that reported by Jardon et al. [27] and slightly less than that obtained by Fowler and Wilkins [28]. The low (3.12\%) - PV observed at day 60 post-AI might be related to the relatively high number of false positive diagnoses. These variations might be explained by several artifacts related to the environment of experimentation and poor contact between the probe and the skin. The most likely source of false positive diagnoses might be embryonic mortality or abortion, which may reach to $30 \%$ in sheep [29]. In addition, abnormal uterine conditions such as pyometra or hydrometra or the presence of intestinal or abdominal fluid may lead to false positive diagnosis, especially in the early stage of pregnancy. When not diagnosed, pseudopregnancy can persist for up to several months, and the volume of the fluid can reach several liters. In such cases the distended abdomen will give the false impression that the animal is pregnant; this can also be accompanied by udder enlargement. Moreover, because the animals were not fasted prior to scanning, the intestinal gas or ingesta may have interfered with the visualization of the pregnant uterus [30]. Fasting animals 12-24 h prior to the scanning reduces the intestinal gases or ingesta, which might interfere with the identification of the pregnant uterus or induce image artifacts [30]. The higher rate of conformity than the discordance confirms that real-time B-mode TU can be used effectively under traditional conditions.

\section{Conclusion}

Real-time B-mode UT has eliminated 59 pregnant goats which could have aborted following hormonal treatment. We recommend that TU should be used widely in the traditional area. This study emphasized the importance of re-examination of goats with negative or doubtful TU diagnoses performed at day 40 post-AI.

\section{Authors' contributions}

JK and MK collected data from the study area and performed the study under the guidance of AS and GJS. JK, AS, MK, and GJS drafted, reviewed and revised the manuscript. All authors read and approved the final manuscript.

\section{Acknowledgments}

The authors would like to thank the PoitouCharentes region (France) which initiated and funded this program, the Ministry of Livestock in Senegal, the regional council of Fatick, the Ancar, the Prolait program, the Fresyca and Mr. Mathieu Gloria.

\section{Competing I nterests}

The authors declare that they have no competing interests.

\section{References}

1. Purohit, G. (2010) Methods of pregnancy diagnosis in domestic animals: The current status. Web. Med. Cent. Repro., 1(12): WMC001305.

2. Torloni, M.R., Vedmedovska, N., Merialdi, M., Betrán, A.P., Allen, T., González, R. and Platt, L.D. (2009) Safety of ultrasonography in pregnancy: WHO systematic review of the literature and meta-analysis. Ultrasound Obstet. Gynecol., 33(5): 599-608.

3. Moraes, E.P.B.X., Santos, M.H.B., Arruda, I.J., Bezerra, F.Q.G., Filho, A.C.R., Neves, J.P., Lima, P.F. and Oliveira, M.A.L. (2007) Hydrometra and mucometra in goats diagnosed by ultrasound and treated with PGF2 $\alpha$. Med. Vet., 1: 33-39.

4. Suguna, K., Mehrotra, S. and Agarwal, S.K. (2008) Early pregnancy diagnosis and embryonic and fetal development using real time B mode ultrasound in goat. Small Rum. Res., 80: 80-86.

5. Padilla-Rivas, G.R., Sohnrey, B. and Holtz, W. (2004) Early pregnancy detection by real-time ultrasonography in Boer goats. Small Rum. Res., 58(1): 87-92

6. Hesselink, J.W. and Taverne, M.A.M. (1994) Ultrasonography of the uterus of the goat. Vet. Q., 16: 41-45.

7. Mialot, J.P., Levy, I. and Emery, P. (1991) Echographie et gestion des troupeaux caprins. Rec. Méd. Vét., 167: 399-406.

8. Djakba, A. (2007) Evaluation of reproduction parameters of the inseminated Sahelian goats and the growth of the kids in the area of Fatick in Senegal. Vet. Thesis Dakar. p. 87.

9. González, F., Cabrera, F., Batista, M., Rodriguez, N., Sulon, J. and Beckers, J.S. (2004) A comparison of diagnosis of pregnancy in the goat via transrectal ultrasound scanning, progesterone, and pregnancy-associated glycoprotein assays. Theriogenology, 62(6): 1108-1115.

10. Hanzen, C.H., Pieterse, M., Szenci, O. and Drost, M. (2000) Relative accuracy of the identification of ovarian structures in the cow by ultrasonography and palpation per rectum. Vet. J., 159: 161-170.

11. Snedecor, G.W. and Cochran, W.G. (1989) In: Statistical Methods. $8^{\text {th }}$ ed. Iowa State University Press, Ames, Iowa, USA. p.125-128.

12. Mpatswenumugabo, J.P. (2009) Monitoring and evaluation of the caprine artificial insemination quality in the rural area of Fatick in Senegal. Vet. Thesis Dakar. p. 122.

13. Kor, N.M., Khanghah, M.K. and Ali, A. (2012) Efficiency of short time protocols based on combined FGA, PGF2 $\alpha$, $\mathrm{GnRH}$ and eCG treatments on oestrus synchronization and reproductive performance of kermani ewes during the breeding season. Int. J. Biol. Med. Res., 3(3): 1966-1970.

14. Omontese, B.O., Rekwot, P.I., Ate, I.U., Rwuaan, J.S. and Makun, H.J. (2013) Comparative estrus induction in indigenous Sahel goats using two progestagens (CIDR and FGA) and eCG. Livest. Res. Rural Dev., 25. Available from: http://www.lrrd.org/lrrd25/4/omon25066.htm. Accessed on 25-04-2014.

15. Kouamo, J., Safari, T., Miguiri, K., Sandeu, M.M. and Sawadogo, G.J. (2014) Study of nutritional parameters in Sahelian goats inseminated at induced estrus (FGA sponge and eCG). Livest. Res. Rural Dev., 26. Available from: http://www.lrrd.org/lrrd26/3/koua26038.html. Accessed on 25-04-2014.

16. Romano, J.E. (2002) Does in proestrus-estrus hasten estrus onset in does estrous synchronized during the breeding season. Appl. Anim. Behav. Sci., 77: 329-344.

17. Karen, A., Szabados, K., Reiczigel, J., Beckers, J.F. and Szenci, O. (2004) Accuracy of transrectal ultrasonography for determination of pregnancy in sheep: Effect 
of fasting and handling of the animals. Theriogenology, 61: 1291-1298.

18. Kouamo, J. and Sawadogo, G.J. (2012) Synchronization rate and factors affecting pregnancy rate after synchronization of estrus cycle and insemination of Gobra zebu (Bos indicus) in traditional area in Senegal. Livest. Res. Rural Dev., 24. Available from: http://www.lrrd.org/lrrd24/11/koua24200. htm. Accessed on 25-04-2014.

19. Omontese, B.O., Rekwot, P.I., Makun, H.J., Obidi, J.A., Rwuaan, J.S. and Chiezey, N.P. (2010) Evaluation of EAZIBREED $^{\text {TM }}$ CIDR $^{\circledR}$ and FGA- $30^{\circledR}$ intravaginal sponges as synchronizing agents in prepartum red Sokoto Does. J. Vet. Res., 3(3): 64-69.

20. Omontese, B.O., Rekwot, P.I., Makun, H.J., Ate, I.U. and Rwuaan, J.S. (2012) Induction of estrus in Sahel goats using fluorogestone acetate (FGA) sponges and equine chorionic gonadotrophin (eCG). Sokoto J. Vet. Sci., 10(2): 21-25.

21. Mbaidingatoloum, F.M. (2003) A protocol of artificial insemination of the Sahelian goats in field conditions: preliminary results. Post graduate diploma in animal productions, Dakar (EISMV), p30.

22. Rwakazina, O. (2005) Evaluation of the productivity in field and station of the Boer goat in Rwanda. Vet. Thesis Dakar. p. 92.

23. Bretzlaff, K.N. and Romano, J.E. (2001) Advanced reproductive techniques in goats. Vet. Clin. North Am. Food Anim. Pract., 17: 421-434.
24. Davey, C.G. (1986) An evaluation of pregnancy testing in sheep using a real-time ultrasound scanner. Aust. Vet. J., 63: 347-348.

25. Taverne, M.A.M., Szenci, O., Szetag, J. and Piors, A. (1985) Pregnancy diagnosis in cows with linear-array real time ultrasound scanning. A preliminary note. Vet. Q., 7: 264-270.

26. Medan, M., Watanabe, G., Absy, G., Sasaki, K., Sharawy, S. and Taya, K. (2004) Early pregnancy diagnosis by means of ultrasonography as a method of improving reproductive efficiency in goats. J. Reprod. Dev., 50(4): 391-7.

27. Jardon, C., De Montigny, G., Andre, D., Corteel, J.M., Baril, G., Cognie, Y., Botero-Herrera, O. and Humblot, P. (1984) Methods of pregnancy diagnosis in sheep and goats. In IX ${ }^{\mathrm{e}}$ Research days in sheep and goats. INRA-ITOVIC, Paris. p. 452-473.

28. Fowler, D.G. and Wilkins, J.F. (1984) Diagnosis of pregnancy and number of the fetuses in sheep by real-time ultrasonic imaging. 1. Effect of number of fetuses, stage of gestation, operator and breed of ewe on accuracy of diagnosis. Livest. Prod. Sci., 11: 437-450.

29. Roberts, S.J. editor. (1971) Infertility in ewes and does. Veterinary Obstetrics and Genital Diseases. Edwards Brothers Inc., Ann Arbor, Ml. p. 579.

30. Sharky, S., Callan, R.J., Mortimer, R. and Klimberling, C. (2001) Reproductive techniques in sheep. Vet. Clin. North Am. Food Anim. Pract., 17: 235-255. 